\title{
Optimal timing of wildfire prevention education
}

\author{
D. T. Butry ${ }^{1}$, J. P. Prestemon ${ }^{2} \&$ K. L. Abt $^{2}$ \\ ${ }^{I}$ Building and Fire Research Laboratory, \\ National Institute of Standards and Technology, USA \\ ${ }^{2}$ Southern Research Station, US Forest Service, USA
}

\begin{abstract}
Public outreach and wildfire education activities have been shown to limit the number of unintentional human-caused ignitions (i.e., 'accidental' wildfires). Such activities include the airing of public service announcements, visiting with homeowners in at-risk areas, distributing informative brochures and flyers, hosting of public forums (with presentations), and facilitating community sponsored neighborhood hazard assessments. By limiting the number of ignitions, prevention entirely avoids costs and losses related to fire suppression (initial attack) and property damage. In this paper, we show that the benefits of wildfire prevention education activities carried out in the State of Florida, USA, far outweigh their costs. We also report how the return on wildfire prevention education investment in that State varies-i.e., the effectiveness of these programs varies - with many exogenous factors, including weather, season, and recent wildfire history and fuels management activities. To illustrate how this effectiveness variation could be exploited to increase returns to money spent on prevention, we explore the optimal timing of wildfire prevention activities. Optimal timing of wildfire prevention education spending is defined as the spending allocation over time that yields the lowest wildfire-induced cost plus net value change to society. We find that, for Florida, the optimal (monthly) timing of prevention activities can be forecasted by exploiting the relationships between prevention effectiveness and fire weather measures, which vary predictably within the year.
\end{abstract}

Keywords: fire economics, wildland-urban interface, hazard mitigation, wildfire prevention, wildfire education. 


\section{Introduction}

Wildfire managers and policy makers have a variety of means for reducing the long-run discounted sum of costs and losses from wildfire. These include preventing and suppressing wildfires, reducing fuels so that fires are less damaging and easier to suppress, and taking steps after a wildfire to minimize the overall impact to a community or ecosystem. Although research has statistically identified the effectiveness of suppression (Butry [1]) and fuel reductions at reducing fire extent and damages (Pollet and Omi [2], Mercer et al. [3]) and lowering the rate of occurrence of certain types of fires (Mercer and Prestemon [4], Prestemon and Butry [5]), up until very recently (Prestemon et al. [6], Butry et al. [7]) the refereed literature had been missing studies documenting the effectiveness of wildfire prevention efforts directed at human-caused wildfires. Governments and other entities devote significant resources to educating the public about the dangers of, and ways to reduce, unintentional firesetting, but the economic justifications for such interventions have been tenuous.

Wildfires are unintentionally ignited through a variety of mechanisms, including by escaped use fire (e.g., debris fire, brush-clearing fires), equipment malfunctions or sparking, escaped campfire, smoking, children-involved fire play, and vehicle crashes. Some of these wildfire starts can be avoided, and agencies have long used policies to prevent them, such as not permitting use fires or campfires when weather conditions are favorable for fire spread. Land management agencies have also undertaken significant programs that involve public education and organization of communities, and this includes encouragement of adoption of less risky technologies (e.g., use of spark arrestors). The rationale behind such programs is that preventing ignitions reduces expenditures required for fuels management and suppression, and because unintentional fires are often due to carelessness, information campaigns can raise awareness. Further, unintentionally ignited fires often occur in places where people and values at risk are in close proximity (Butry et al. [8]). Because people are often involved in the wildfire start, and because these fires occur in an intermix of high value property and local populations (e.g., Bradshaw [9]), such fires produce immediate peril to people and property close by.

In this paper, we extend the methodologies and models developed in Prestemon et al. [6] and Butry et al. [7] that were used to: (1) evaluate the benefit-cost performance of wildfire prevention effort in the state of Florida (Prestemon et al. [6]), and (2) determine the optimal mix of wildfire prevention effort and fuels management to yield the least cost-plus-loss of wildfire management (Butry et al. [7]). We extend that research by estimating the optimal timing of wildfire prevention activities such that it yields the least costplus-loss while holding fuels management activity constant.

\section{Wildfire prevention effectiveness in Florida}

The effectiveness of wildfire prevention can be measured both in terms of the number of wildfires prevented per unit of wildfire prevention applied and in 


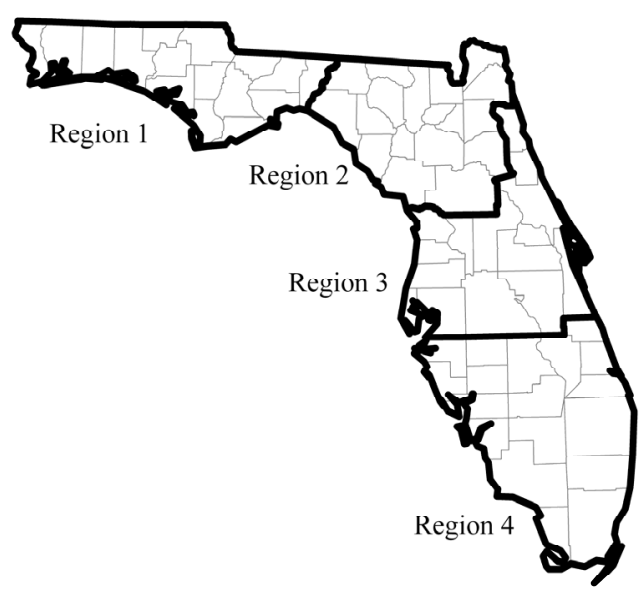

Figure 1: Fire management regions (black outline) and counties (gray outline) in Florida.

terms of damages averted per unit of wildfire prevention. Calculating the returns to wildfire prevention is straightforward and derives directly from equations of wildfire starts modeled empirically as a function of prevention and a variety of other variables, including fuels management, weather, historical wildfire, and socioeconomic measures.

Prestemon et al. [6] estimated the effect of wildfire prevention effort on the number of 'targeted' wildfire ignitions in the four wildfire management regions of Florida (see fig. 1) from 2002-2007.

Targeted wildfire ignitions include unintentionally ignited wildfires caused by escaped campfires and debris fires, discarded cigarettes, and children playing with fire. These wildfires accounted for 320 ignitions on average per year, over the study period, and occurred mostly during the winter (December, January, and February) and spring months (March, April, and May) (see table 1). Overall, targeted wildfires accounted for $36 \%$ of all wildfires in Florida during this time. Debris fires caused $23 \%$ of all ignitions, followed by campfires $(7 \%)$, children (5\%), and smoking (1\%) (see fig. 2).

Five wildfire prevention activities carried out by wildfire mitigation specialists in the State of Florida were evaluated: (1) media public service announcements (PSAs) broadcast to the general public, which included the number of TV, radio, newspaper PSAs, and activities performed by wildfire prevention specialists, including (2) homes visited, (3) presentations given, (4) brochures distributed, and (5) community-based wildland hazard assessments. Although there were other kinds of prevention education activities recorded by wildfire mitigation specialists, these were too limited to enable their inclusion in the statistical analysis we conducted. The average timing of the five activities evaluated is shown in table 1. For all activities, except homes visited, their peak 
occurred in the spring months (March, April, and May). This peak coincided with the peak wildfire activity of all causes (targeted plus non-targeted wildfires). Note, however, many of the targeted types of ignitions preceded prevention and began in the prior winter. This suggests an opportunity for better timing of wildfire prevention activities, so that the message gets out before the relevant wildfire season begins.

Table 1: $\quad$ Annual wildfire prevention effort and fire activity in Florida, 20032007.

\begin{tabular}{ccccccc}
\hline & \multicolumn{7}{c}{ Averages } \\
PREVENTION & Spring & Summer & Fall & Winter & Monthly & Total \\
\hline Media PSAs & 910 & 238 & 167 & 252 & 130 & 1,566 \\
TV & 400 & 89 & 53 & 89 & 53 & 632 \\
Radio & 180 & 72 & 54 & 71 & 31 & 377 \\
Newspaper & 330 & 77 & 59 & 91 & 46 & 557 \\
Homes Visited & 84 & 184 & 51 & 58 & 31 & 377 \\
Presentations & 13 & 8 & 7 & 18 & 4 & 45 \\
Brochures & 2,549 & 1,560 & 975 & 3,884 & 747 & 8,968 \\
Assessments & 2 & 2 & 2 & 2 & 1 & 8 \\
FIRE & & & & & & \\
Rx fire acres & 47,025 & 12,349 & 10,492 & 69,900 & 11,647 & 139,766 \\
Rx fire permits & 298 & 54 & 60 & 473 & 74 & 886 \\
Targeted & 143 & 27 & 32 & 118 & 27 & 320 \\
Ignitions & & & & & & \\
Non-targeted & 232 & 172 & 47 & 95 & 46 & 546 \\
Ignitions & & & & & & \\
\hline
\end{tabular}

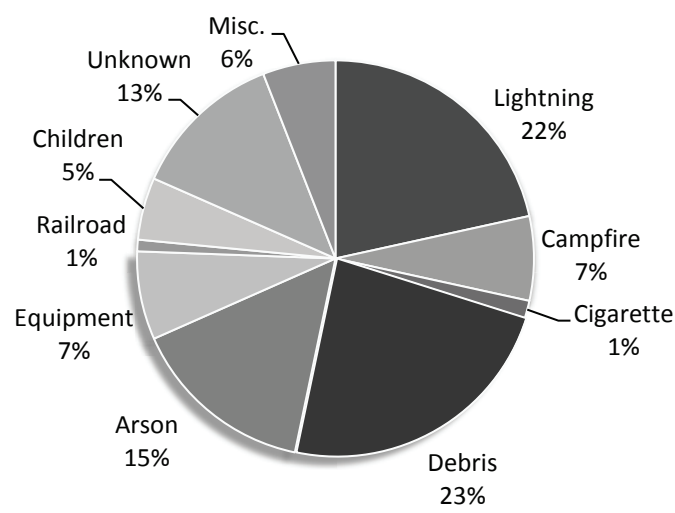

Figure 2: $\quad$ Percent of all wildfire ignitions by wildfire cause in Florida, 20022007. 


\section{Methods}

Using the modeling results from Prestemon et al. [6] and Butry et al. [7], we explore how changes in the timing of prevention activities affect the social costplus-loss of wildfire management. These studies relate wildfire prevention effort to the number of targeted wildfire ignitions while accounting for other exogenous factors. Table 2 presents the elasticities of targeted wildfire ignitions with respect to wildfire prevention effort (i.e., the percent change in the number of targeted ignitions due to a corresponding $1 \%$ change in wildfire prevention effort) reported in Prestemon et al. [6]. This shows the effect prevention has on the numbers of fire starts. For instance, a $10 \%$ increase in media PSAs is expected to cause a $1.7 \%$ decrease in the number of targeted wildfire ignitions in the month that the PSAs were run, and another $2.6 \%$ decrease in ignitions over the following six months, for a total reduction of more than 13 fire starts. As a comparison, the elasticity of targeted wildfire ignitions with respect to prescribed fire ranged from -0.18 to -0.34 , depending when treatments had last occurred (1 to 3 years prior). Thus, wildfire prevention and prescribed fire have similar elasticities, but because the effect of prescribed fire is longer lived, the total reduction is larger (over time, nearly 17 fewer fire starts for a $10 \%$ increase in prescribed fire).

Table 2: Elasticities of targeted wildfire ignitions with respect to wildfire prevention effort.

\begin{tabular}{cc}
\hline Wildfire Prevention Activity & Elasticity \\
\hline Media PSAs: 1-6 months prior & -0.26 \\
Homes Visited: 1-6 months prior & 0.04 (not significant) \\
Presentations: 1-6 months prior & -0.22 \\
Brochures: $1-6$ months prior & -0.24 \\
Assessments: 1-6 months prior & 0.07 (not significant) \\
Media PSAs: current month & -0.17 \\
Homes Visited: current month & -0.03 \\
Presentations: current month & -0.23 \\
Brochures: current month & -0.14 \\
Assessments: current month & -0.12 \\
\hline
\end{tabular}

Butry et al. [7] determined that a strategic coordination of wildfire prevention with prescribed fire treatments could be used to reduce the numbers of targeted wildfires in an economically efficient manner. Figure 3 shows the cost-plus-loss surface of wildfire management, drawn as a function of wildfire prevention effort and prescribed fire activity. It was found that increasing wildfire prevention by $168 \%$, combined with increasing prescribed fire treatment by $74 \%$, reduced the cost-plus-loss of wildfire management from $\$ 325$ million to $\$ 301$ million. This expansion of these wildfire management programs resulted in \$24 million in net benefits to the state of Florida, and that no other combination of prevention and fuels management would deliver a larger economic return. 


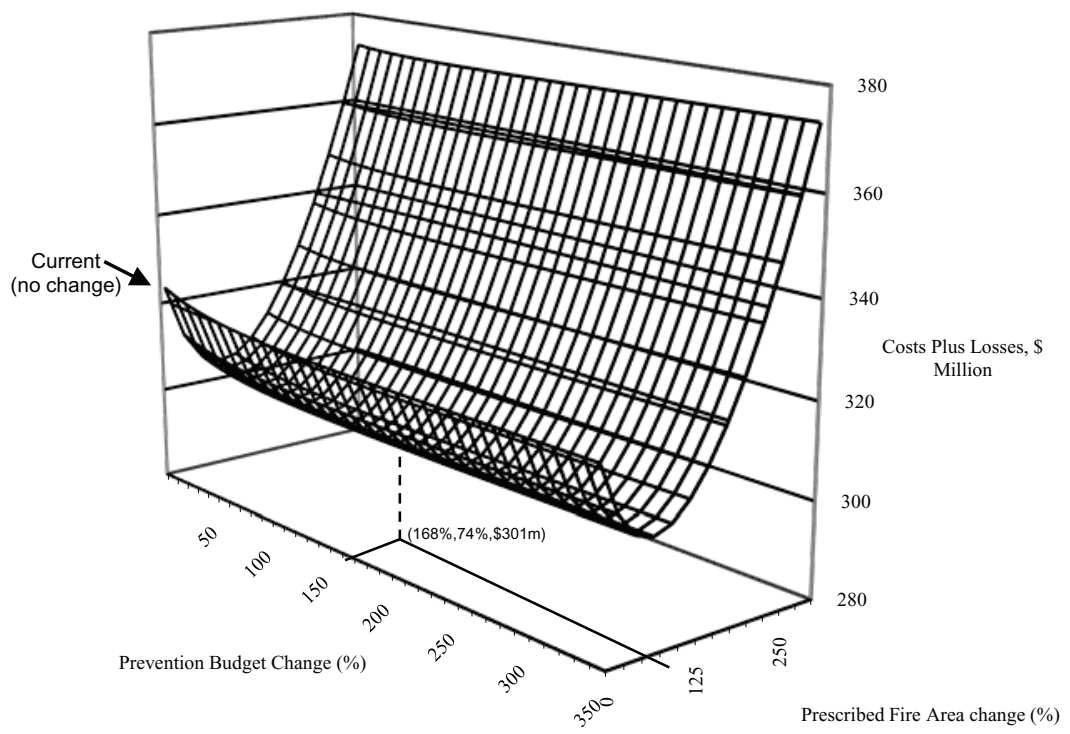

Figure 3: Wildfire mitigation trade-off: wildfire prevention effort versus prescribed fire fuel treatments.

Of course, actually expanding the number or size of prescribed fire treatments in Florida may be difficult. Unlike wildfire prevention, fuel treatments are largely conducted by the private sector, on private lands, making it difficult to coordinate an optimal response. Therefore, we explore how changes in (1) the timing of prevention activities, (2) the prevention budget, and (3) both the timing and budget of prevention can be used to reduce the cost-plus-loss of wildfire management, all while assuming a fixed level of prescribed fire treatment.

\section{Optimal timing of wildfire prevention effort}

We examine how the regions in Florida could time wildfire prevention effort throughout the year to minimize the cost-plus-loss of wildfire management. The timing of the prevention activities are chosen to maximize their effect throughout the wildfire season, while explicitly accounting for the short-run effect of prevention messages (i.e., message effectiveness seems to last six months from the month they were delivered) and the longer-run negative feedback (fuel accumulation) effect. We assume shifts in prevention effort within the year are feasible. We recognize that this may be challenging with fixed staffing levels.

We evaluate two scenarios: (1) assuming a constant prevention budget and (2) allowing for a change in prevention spending. The first scenario explores "what can be done" given the same budget. The second scenario explores "what could be done" with budget flexibility. Both scenarios are run assuming either that (a) individual regions can change their spending patterns across months differently, or that (b) all regions must change their spending patterns equally, by the same 
percentage across all months, statewide. In addition, we estimate the economic impact of each scenario by estimating the associated cost-plus-loss incurred from changes in wildfire prevention effort.

\subsection{Budget: no change}

Figure 4 presents the change in wildfire prevention effort for the state (overall) and for the four regions, for the fire years of 2003 to 2007, given no change in the current budget. The model was constrained so that the largest reduction in spending allowed in any month was $99 \%$ compared to base level spending. As can be seen, large increases in prevention activity are warranted from January through March, at the expense of activity in the summer and at the beginning of the winter. All regions require large increases in February and March, with Regions 2, 3, 4 also requiring large increases in January. Unlike the other regions, it is more effective to target ignitions later in the year (April) than earlier (January) in Region 1. This result may be linked to the ecological and climatic differences of that part of the state relative to others.

Economically, altering the monthly timing of wildfire prevention activities is expected to yield statewide net benefits of $\$ 3.9$ million, for the scenario when all regions are required to change their spending by the same amounts (see table 3 ). When allowed to change independently at different rates, the net benefits increase to $\$ 4.3$ million over the five years in total. The largest net benefits

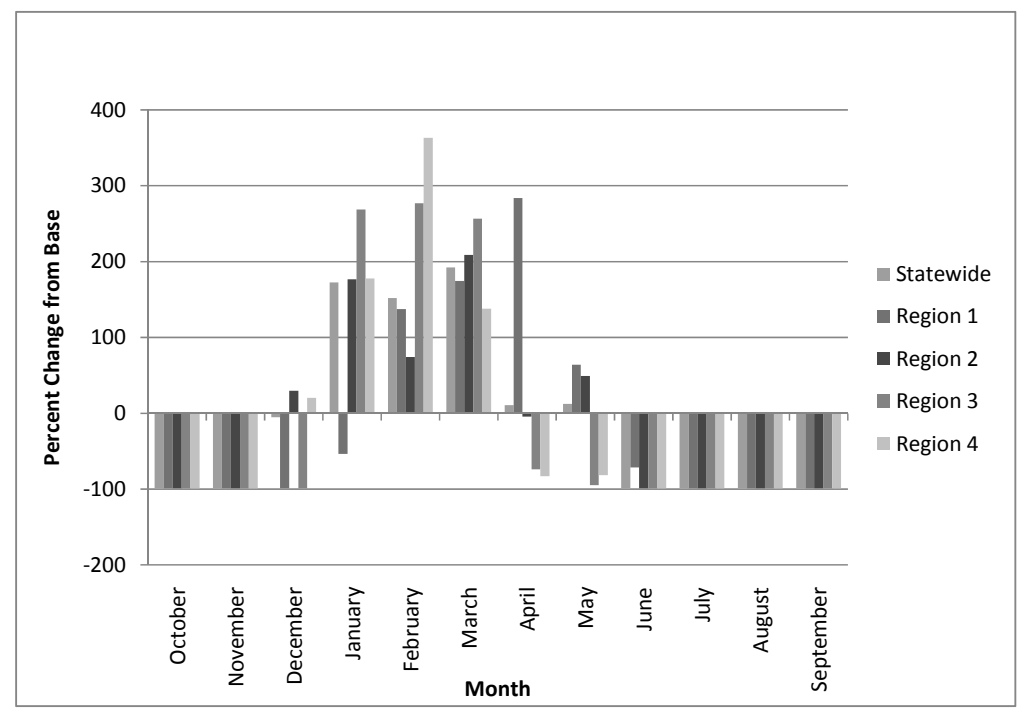

Figure 4: Optimal timing of wildfire prevention effort with no change in prevention spending, statewide and individually by region. 
Table 3: Economics of altering the timing of wildfire prevention effort with no change in prevention spending (shown in thousands of U.S. dollars), totals summed over 2003 to 2007.

\begin{tabular}{cccccc}
\hline & Statewide & Region 1 & Region 2 & Region 3 & Region 4 \\
\hline Base spending & 2,228 & 557 & 557 & 557 & 557 \\
Total spending & 0 & 0 & 0 & 0 & 0 \\
change & & & & & \\
Rx fire spending & 12,850 & 5,796 & 1,755 & 2,769 & 2,531 \\
Wildfire losses & 306,857 & 17,209 & 68,455 & 28,178 & 192,623 \\
Total cost + loss & 321,935 & 23,561 & 70,767 & 31,503 & 195,711 \\
Base cost + loss & 325,825 & 23,673 & 74,327 & 31,776 & 196,049 \\
Change in cost + loss & $-3,890$ & -112 & $-3,560$ & -272 & -338 \\
\hline
\end{tabular}

would accrue to Region 2, at $\$ 3.6$ million. Again, these returns occurred from just altering the timing of prevention messages and could be done without any additional spending. While such spending adjustments may involve hidden costs that we cannot account for, at least for the costs that we can account for, the benefit-to-cost ratio implied by such a change is essentially infinite. This demonstrates how important it is for prevention messages to get out ahead of the forthcoming wildfire season.

\subsection{Budget: increase}

Figure 5 presents the change in wildfire prevention effort for the state (overall) and for the four regions, for the fire years of 2003 to 2007, given an increase in prevention spending. The size of the spending increase was determined by minimizing the cost-plus-loss of wildfire management while allowing for increases in wildfire prevention spending. As in the fixed budget scenario, the simulation was constrained so that the largest reduction in spending allowed in any month was $99 \%$ compared to base levels. Note, the overall timing pattern is similar to the one with a fixed budget, with January through March receiving most of the increases. We find that the size of the overall increases are larger than with the fixed budget. The largest monthly increases range from $152 \%$ to $192 \%$ in the fixed budget case, but from $253 \%$ to $331 \%$ in the increased spending case. Even though increases in the prevention budget are justified on economic grounds, these increases are targeted to certain times of the year. We find little support for large prevention campaigns in June through October, regardless of budget.

Economically, altering the monthly timing of wildfire prevention activities with greater funds available to support an expansion wildfire prevention effort yields statewide net benefits of $\$ 4.4$ million (see table 4). Again, the largest net benefits would accrue to Region 2, at $\$ 3.7$ million. Supporting such economic returns would require an additional $\$ 1.0$ million of prevention funding over the 2003 to 2007 period if equal changes were imposed across all regions. This represents a $45 \%$ increase in wildfire prevention spending under the statewide scenario and $34 \%$ when individual regions are allowed to change their spending 


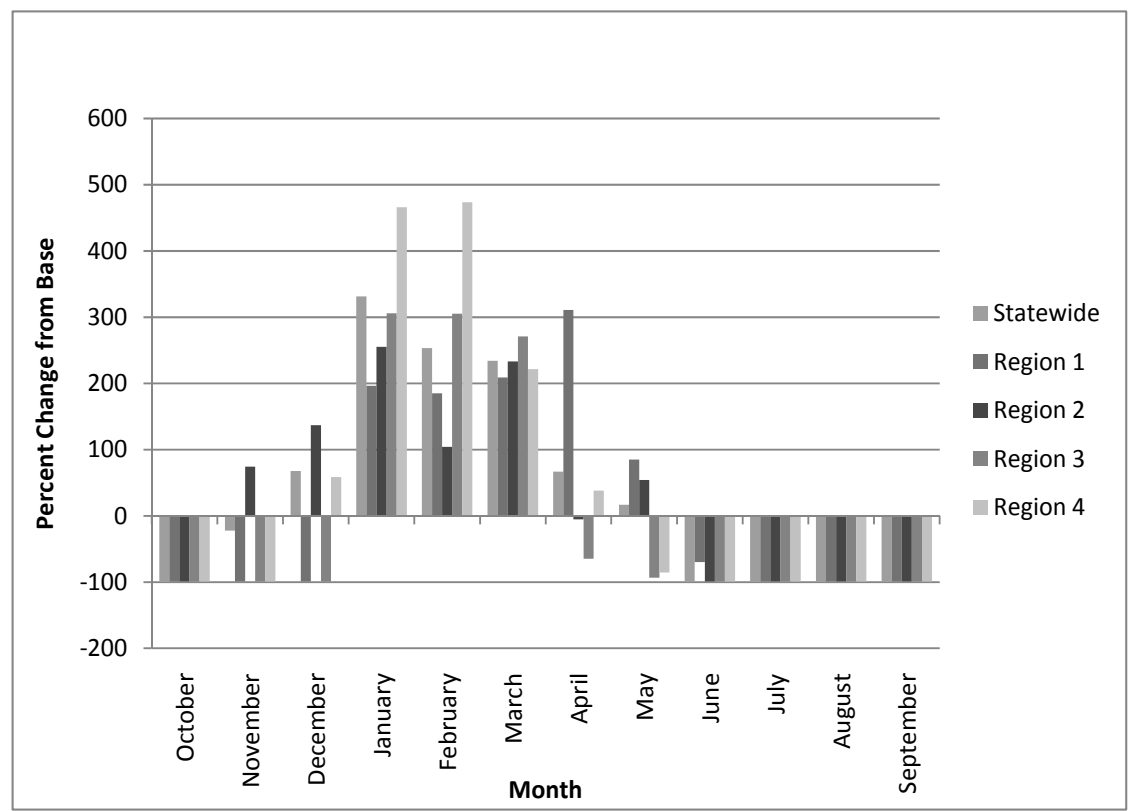

Figure 5: Optimal timing of wildfire prevention effort with an increase in prevention spending.

Table 4: Economics of altering the timing of wildfire prevention effort with an increase in prevention spending (shown in thousands of U.S. dollars), totals summed over 2003 to 2007.

\begin{tabular}{cccccc}
\hline & Statewide & Region 1 & Region 2 & Region 3 & Region 4 \\
\hline Base spending & 2,228 & 557 & 557 & 557 & 557 \\
Total spending & 1,001 & 187 & 204 & 44 & 312 \\
$\begin{array}{c}\text { change } \\
\text { Rx fire spending }\end{array}$ & 12,850 & 5,796 & 1,755 & 2,769 & 2,531 \\
Wildfire losses & 305,344 & 16,974 & 68,104 & 28,131 & 192,092 \\
Total cost + loss & 321,424 & 23,513 & 70,620 & 31,501 & 195,492 \\
Base cost + loss & 325,825 & 23,673 & 74,327 & 31,776 & 196,049 \\
Change in cost + & $-4,401$ & -160 & $-3,707$ & -275 & -557 \\
loss & & & & & \\
\hline
\end{tabular}

patterns differently. While this increase may be seen as significant, the $\$ 1.0$ million directly returns $\$ 5.4$ million in reductions in wildfire losses. This return represents a 5.4 benefit-to-cost ratio. When individual regions are allowed to change differently, the net benefits are even higher, with additional costs over the 5-year period totaling $\$ 0.75$ million, yielding a reduction in losses of $\$ 5.4$ million, implying a benefit-to-cost ratio of 7.3. 


\section{Conclusion}

We have shown that the benefits of wildfire prevention and education activities far outweigh their costs. However, the return on investment varies-i.e., effectiveness of these programs - with many exogenous factors, including weather, recent wildfire history and fuel management activities, and season. Given this, we explored the optimal timing of wildfire prevention activities that yield the least wildfire-induced cost-plus-loss to society. We find that, for the State of Florida, changes in the monthly timing of wildfire prevention activity can pay dividends to society. Simply shifting prevention activities to occur during more winter months can produce net benefits of \$3.6 million (assuming similar annual trends [e.g., weather] as occurred from 2003 to 2007). Increases in wildfire prevention spending, of $34 \%$ to $45 \%$, coupled with the expansion of prevention effort in the winter and spring months are estimated to produce $\$ 4.4$ million in net benefits.

\section{References}

[1] Butry, D.T., Fighting fire with fire: estimating the efficacy of wildfire mitigation programs using propensity scores. Environmental and Ecological Statistics, 16, pp. 291-319, 2009.

[2] Pollet, J., \& Omi, P.N., Effect of thinning and prescribed burning on crown fire severity in ponderosa pine forests. International Journal of Wildland Fire, 11(1), pp. 1-10, 2002.

[3] Mercer, D.E., Prestemon, J.P., Butry, D.T., \& Pye, J.M., Evaluating alternative prescribed burning policies to reduce net economic damages from wildfire. American Journal of Agricultural Economics, 89(1), pp. 6377, 2007.

[4] Mercer, D.E., \& Prestemon, J.P., Comparing production function models for wildfire risk analysis in the Wildland-Urban Interface. Forest Policy and Economics, 7(5), pp. 782-795, 2005.

[5] Prestemon, J.P., \& Butry, D.T., Time to burn: modelling wildland arson as an autoregressive crime function. American Journal of Agricultural Economics, 87(3), pp. 756-770, 2005.

[6] Prestemon, J.P., Butry, D.T., Abt, K.L., \& Sutphen, R., Wildfire Prevention Efficacy: Marginal and Non-marginal Benefit to Cost Ratios. Forest Science, In press.

[7] Butry, D.T., Prestemon, J.P., Abt, K.L., \& Sutphen, R., Economic optimization of wildfire intervention activities. International Journal of Wildland Fire, In press.

[8] Butry, D.T., Pye, J.M., \& Prestemon, J.P., Prescribed fire in the interface: separating the people from the trees. Proc. of the Eleventh Biennial Southern Silvicultural Research Conference, ed. K. Outcalt, Gen. Tech. Rep. SRS-48, USDA Forest Service, Ashville, pp. 132-136, 2002.

[9] Bradshaw, W.G., Fire protection in the urban/wildland interface: who plays what role? Fire Technology, 24(3), pp. 195-203, 1988. 